\title{
SULPANILAMIDA. Y DERIVADOS EN LAS ENTERITIS DEL LACTANTE
}

Poc el Prof. VICTOR ZERBINO.

(Montevideo).

Desde que conocimos, gracias a las investigaciones bacteriológicas de E. Hormaeche, C. A. Peluffo, N. Surraco y P. A. Aleppo (1) la gran difusión de Shigellas $y$ de Salmonelias en nuestro medio y su importante intervención en la determinación de diarreas en nuestros niños (de 20: a $40 \%$ de diarreas en niños de 0 a 2 años, según épocas, y estaciones, son determinadas por aquellas); desde que apreciamos la gravedad de esas enteritis, documentada en el Informe de la Sociedad Uruguaya de Pediatría a la X Jornada Pediátrica Rioplatense (2). y según el cual la mortalidad oscilaba alrededor del $56 \%$ para las shigelósicas, y del $39 \%$ para las salmonelósicas en el primer año de vida, se nos presentó el problema de la profilaxia y del tratamiento de esas mortíferas afecciones. De la profilaxia no nos ocuparemos ahora: pero nos teferiremos al tratamiento, el cual, hasta hace poco. nos depataba las más grandes decepciones por la ineficacia de una terapéutica que casi se reducía a los recursos dietéticos.

Ante un problema tan serio, aun sin solución terapéutica específica satisfactoria, se podía y se debía esperar que se pudiera sacar algún partido útil de la nueva panacea antiinfecciosa, esas sulfanilamidas cuyo campo de acción se ha ensanchado día a día.

Experimentalmente, en animales, ya en 1937, G. A. H. Buttle (3) fué el primero en comprobar su acción sobre ratas infectadas con bacilo disentérico. Este constató que las ratas resistian una inoculación mortal de bacilo disentérico Sonne, cuando recibían 0 gr. 025 de sulfanilamida, dos veces por día. durante siete dias. 
Posteriormente, esos hechos fueron confirmados, para la sulfanilamida y para sus derivados, por otros autores. $y$ entre ellos, C. A. Lawrence (4), R. L. Libby y H. L. Joyner (5). C. H. Rammelkamp y M. L. Jewel (6), y últimamente, en este año 1941, por M. L. Cooper y H. M. Keller (7). Estos autores han comprobado experimentalmente en ratas, una acción bacteriostática, y aun bacteriolítica, de la sulfanilamida y de sus derivados (sulfapiridina, sulfatiazol, sulfametiltiazol, sulfafeniltiazol) no solamente sobre los bacilos disentéricos, sino también sobre otros gérmenes del grupo colo-tífico-disentérico como b. coli, b. lactis aerógenes, b. proteus, E. tiphi, S. paratiphi, S. Schottmuelleri, Sh. disenteriae, Sh. Sonnei. Ellos comprobaton también quc, ya sea in vitro, ya sea en el animal, mientras la sulfanilamida era poco activa, el sulfatiazol era el agente más eficaz; y por otra parte, el germen más sensible a esa acción era el b. paradisenteriae (Flexner).

En 1940, R. D. Muir, V. Shamleffer y L. R. Jones (8) comunican sus observaciones sobre la acción protectora del sulfametiltiazol sobre la infección experimental del ratón por salmonella enteritidis. Mientras los animales controles inoculados con cierta dosis de $\mathrm{S}$. enterítidis morian en un plazo de siete dias, los animales tratados con sulfametiltiazol resistían, según la forma de tratamiento, de cinco a siete veces más.

En el terreno de la aplicación clínica, basta 1940, los resultados fueron nulos en las infecciones tíficas y paratíficas, y dudosos en las disentéricas, como lo señalara B. W. Carey (9). La utilización del sulfatiazol, que difundió recièn en 1940, pudo demostrar una mayor positividad de eficacia.

En nuestro Uruguay, la primera aplicación conocida de las sulfamidas en las enteritis corresponde a F. Abente Haedo y A. Rodríguez Devicenzi (10). Ellos llamaron la atención sobre los resultados favorables obtenidos con la medicación oral con Prontosil, con Dagenan y otra suifopitidina, en cinco casos de disentería a Flexner, señalando cinco curaciones rápidas. De esos casos, uno se refería a un lactante de 10 meses; dos eran niños de 3 y 4 años, y dos etan adnltos. Ellos citan un solo caso de enteritis a S. tiphi murium en un niño de 6 años, en el cual el tratamiento con sulfanilamida no dió resultado favorable. Esta publicación, que es la primera que se refiere concretamente a la disentería del niño, apareció algo retardada, recién a fines de 1940 , 
por lo que la desconocíamos cuando iniciamos nuestros ensayos en Agosto-Setiembre de 1940, primero con sulfanilamida y sulfopiridina, y luego, desde Octubre, con el sulfatiazol.

Más recientemente, en Abril de este año 1941, el Prof. J. M. Valdés y J. B. Sosa Gallardo (de Cordtoba, R. A.) publican el resultado de sus experiencias en el tratamiento de la disentería shigelósica por e! Sulfaminotiazol (Sulfatiazol) (11). En 10 casos en niños de 5 a 18 meses (4 a Flexner y 6 a Shiga) obtienen espléndidos resultados. con mejoria de los sintomas en 24 horas y normalización en 3 días.

También en Abril de este año, Grant Taylor: de EE. UU. (12), refiere buenos resultados en un grupo de niños con diarrea (enteritis específica, enteritis no especificadas, diarreas paraenterales) tratados con sulfatiazol, grupo que conpara con otro semejante, de la misma serie de ingresos, tratado $(\mathrm{C}$ n suere específico (antidisentérico), con drogas, y con el mismo régimen dietético. En el grupo tratado con sulfatiazol (niños de 2 a 26 meses, de los cuales 4 casos de disentería a Flexner, 4 de disentería no especificada, y 5 de diarrea paraenteral) se nota descenso tápido de la fiebre, corrección de la diarrea entre 2 y 6 días (en media. 3.2 dias), curando todos en breve término. En el grupo no tratado icn sulfatiazol, la duración media fué de 15.6 días, la evolución más grave, falleciendo dos de ellos.

Más recientemente aún, F. J. Menchaca y L. Moyano Centeno (13). (de Rosario, R. A.) publican también resultados íavorables obtenidos en unos veinte niños pequeños afectados de enterocolitis disenteriforme no especificada, tratados por el sulfatiazol.

No conocemos publicación alguna chilena que se refiera concretamente a este punto. En la nota "Sulfathiazo' en Pediatría" de W. Bustamante IEspinoza (Rev. Chilena de Ped., XII, 231, Marzo de 1941), y en aquella otra "Los Sulfonamidos", de O. Correa Bórquez (Rev. Chilena de Ped., XII, 530, Julio de 1941), se bace referencia a los trabajos experimentales de Cooper y Keller, y a las aplicaciones clínicas de Taylor y de Valdés y Sosa Gallardo.

Nosotros, con A Norbis y P. A. Alppo, hemos observado la evolución de 55 casos de enteritis tratados con diversas sulfanilamidas, en niños de 2 a 24 meses, en el transcurso de Agosto de 1940 a Abril de 1941. Desde Octubre de $1940^{\circ}$ usamos casi exclusivamente el Sulfatiazol. Los restiltados fueron comunicados a la Sociedad Uruguaya de 
Pediatria en Junio de 1941 (14). De esos 55 casos, no hicimos estado, en nuestra comunicación, sino de 19, en los cuales las comprobaciones bacteriológicas nos permitían identificar a 8 de ellos come enteritis shigelósicas (por b. paradisenterias Flexner). y 11 como enteritis salmonelósicas ( 6 por S. typhi murium: 3 por S. Newport; $y 2$ por $S$. Montevideo). Tanto en estos casos como en aquellos ro identificados, el resultado del tratamiento fué semejante.

En el grupo de las enteritis disentéricas a Flexner, un caso presentó forma clínica benigna, cinco desarrollaron forma severa, y dos la forma grave disentérico-coleriforme con deshidratación $y$ acidosis. Esto en niños de 3 a 17 meses. De ellos, 6 casos fueron tratados con Sulfatiazol, 1 con Sulfanilamida y 1 con Sulfapiridina. Todos curaron.

El tratamiento eliminaba todo otro recurso terapéutico, salvo aquellos destinados a combatir la deshidratación y la acidosis. La dietética se hizo con babeurre simple o papilla de babeurre para los lactantes más tiernos; con papillas de harinas, sopas de harinas en caldo de carne, manzanas y bananas, para los mayores. En la generalidad de los casos no se hizo dieta hídrica, o ésta fué muy breve.

Tanto una como otra sulfonamida fué suministrada por vía oral a la dosis de 0 gr. 20 a 0 gr. 40 por kilogramo de peso corporal y por día. Como dosis inicial dimos la mitad de la dosis diaria. Las tomas se fraccionaban cada cuatro hozas para el Sulfatiazol, cada seis para las otras sulfonamidas. Cada toma se hacía antes de una comida, y la dosis era suspendida en apreciable cantidad de agua. Suministramos liquido ligeramente alcalino ad libitam. El tratamiento se prolongó entre 5 y 10 días, sosteniéndole por dos o tres días después de ceder la fiebre, el estado tóxico y la diarrea, habiéndose dado, en total. de 6 a 13 gramos de una u otra droga.

Señalemos que la tolerancia fué buena en general, especialmente para el Sulfatiazol, no habiendo observado trastorno alguno, salvo en el uso de la sulfapiridina.

Destaquemos, desde luego, que el Sulfatiazol se demostró muy superior a las otras sulfonamidas, por su acción sobre los síntomas y sobre la evolución de la enfermedad. Con el Sulfatiazol, la fiebre y el estado toxi-infeccioso desaparecen en uno a tres días: las deposiciones se modifican favorablemente, haciéndose grumelosas y pastosas, en dos a cuatro días; el tenesmo y los pujos ceden en 24 a 60 horas: el apetito vuelve rápidamente, y la reparación nutritiva se 
hace en breve término por la pronta normalización del ape. tito y de las funciones digestivas. Juzgando la curación sobre la base de la desaparición del estado toxi-infeccioso. de la fiebre, de los vómitos y de la diarrea, de la normalización del apetito y de la vuelta del peso corporal a su nivel anterior a la enfermedad, nuestros enfermitos tratados con Sulfatiazol curaron en una media de 7.8 días. Con las otras sulfonamidas, la evolución fué más lenta, curando en un plazo entre 12 y 16 dias. Agreguemos que no observamos ningún caso de recaída, siempre que el tratamiento se prolongó en los primeros días de convalecencia.

En el grupo de las enterítis salmonelósicas debemos señalar que en dos casos se desarrolló una forma enterocolítica común; en siete casos, una forma disentérica severa; y en los otros dos, una forma disentérico-coloriforme grave, con trastornos respiratorios de tipo bronconeumónido. De esos casos, 7 fueron tratados con Sulfatiazol, 3 con Sulfanilamida y 1 con Sulfapiridina. El tratamiento se estableció sobre las mismas bases expresadas. En esta serie encontramos dos fallecidos, casos que comentaremos, tratados con Sulfanilamida. Todos los tratados con Sulfatiazol, curaron.

La impresión recogida en nuestras observaciones (las primeras referentes a este tratamiento en estas enteritis) es que Sulfatiazol y Sulfapiridina son de buena utilidad, destacándose especialmente el Sulfatiazol. Todos los enfermitos tratados con éste, curaron en un plazo medio de 7 días. a pesar de tratarse de formas severas, complicadas con estados catarrales respiratorios; la fiebre (cuando la hubo) cedió en 2 a 3 días. las deposiciones mejoraron en el mismo plazo, y la reparación se hizo en muy buenas condiciones. Un solo caso presentó evolución irregular, prolongada; pero este caso puede explicarse por tratarse de un niño afectado por múltiples localizaciones infecciosas (bronquitis, otitis supurada, pielitis), así como por infracciones en el tratamiento.

Lcs dos casos fatales no deben impresionar mucho nuestro juicio. En primer lugar fueron tratados con Sulfanilamida. y ésta es reconocida, por los hechos experimentales. como la menos activa sobre estos gérmenes. Luego, se tra. taba de niños que llegaron tarde a nuestra asistencia, con graves lesiones broncopulmonares en terreno profundamente deshidratado $e$ intoxicado. Sin embargo, tenemos la impresión por esos $y$ por otros hechos observados, que las formas graves, con lesiones broncopulmonares, y con otras lesiones 
de tipo septicémico en múltiples órganos, son poco sensibles a las sulfonamidas.

El Sulfatiazol nos parece bien útil en el tratamiento de las enteritis salmonelósicas, ya que reduce su evolución de 15 a 40 días, habitual con otros tratamientos, a sólo 6 a 7 días; corrige rápidamente su sintomatología, y adelanta la reparación. Pero, para esto es preciso llegar en los primeros días, antes de que se establezcan múltiples lesiones.

$Y$, por último, dos palabras sobre la Sulfanilguanidina, una de las sulfonamidas más indicadas para el tratamiento de las enteritis disentéricas. Nuestra experiencia es pequeña. pues recién la estamos aplicando en el empuje endémico de este año. Pero, sobre la base de unos 10 casos observados, podemos adelantar: que ella no nos parece más eficaz que el Sulfatiazol en las enteritis shigelósicas; $y$ que ella no tiene ninguna utilidad en las enteritis salmonelósicas, las que hemos visto ceder, en cambio, sustituyendo la Sulfanilguanidina por el Sulfatiazol; por lo tanto, ante un caso de enteritis, aun no identificada, será preferible recurrir al Sulfatiazol.

Víctor Zetbino.-Montevideo, Uruguary, Calie Sariano 1507.

1.-Inf. de Soc. Urug. de Ped., "Estudios sothe la etiología infecciosa de las diarreas infantiles". X Jornada Ped. Rioplatense; Montevideo, 1940.

2.- Dhem. y ZERBiNo $V_{\text {.: }}$ Las enteritis en primeta infancia, Arch. Argent. Ped., 15, 3, $194 \mathrm{~J}$.

3.-BUtTle G. A. H. - Pros, Roy, Soc. Méd, 3J, 154, 1937.

4.-LAWRIENOE, C. A. - Bacteriostatic effects of sulfobanilamide and its pyridine and thiazole derivatives apon colon-typhoid-dysentery group. Proc. Soc. Exper. Biol. and Med., 44, 162, 1940.

5.- ILIBBY R. L. Y JOYNER A. L. - Action, of Sulphathiazole en colontrphoid-dysentegty group of organisms. J Infect. Dis, 67, 67, 1940.

6.-RAMMELKAMP C. H. y MEWELI M. L'. - Comparativo in virro Study of various Sulphanilamide on Tiyphoid-dysentery Organisms. Proc. Sor. Exper. Biol. and Med., 45, 169, 1940.

7.-COOPER M. L. y KIELEEER H. M. - Sulphonamide Drogs in the Traitmenc of Experimental Dysentery Infection in mice. J. of Ped., 18 , 459,1941 .

8.-MUIR R. D. SHA.MLEFFER V. $y$ JONES L. R. - Protective effect of Sulphamethylthiazole on experimental Salmonetla Enteritidis infection in mice. Proc. Sor. Expert Biol. and Med,, 45, 31, 1940.

9.-CAREY B. V. — Sulphanilamides in Diseases of Infancy and Chiltbood. J. A. Am. Med. Ass., 1 1'5, 924, 1940. 
10.-ABENTE HALDE F. Y RODRLGUEZ DEVICENZI A. - La disentería bacilar y su tratamiento por la Sulfanilagita. Arch. Urug. Med. Cir. y Espec., 17, 245, 1940.

31.-VALDES J. M. y SOSA GALLARDO J. B. - Tratamiento de la dizentería con el Salfoaminotiazol. Arch. Argent. Ped., 15, 338, 1941.

12.-TAYLIGR G. - Sulpbathiazole Therapy of Infantike Diarnhea. J. of. Ped.. 18. 469. 1941.

13. MENCHACA F, y MOYANO CENTENO L. - EI SDlfatiazol en las enterocolitis disenteriformes. Atch. Argent. Ped., 115, 432. 1941.

14.-ZERBINO V., NORBIS A. y AilEPPO P. A. - Arch. Urug. Med. Cir. y Espec., 19, 1, 1941. 